\title{
Respiratory responses to hypoxia/hypercapnia in small for gestational age infants influenced by maternal smoking
}

\author{
B C Galland, B J Taylor, D P G Bolton, R M Sayers
}

Arch Dis Child Fetal Neonatal Ed 2003;88:F217-F222

See end of article for authors' affiliations

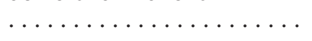

Correspondence to: Dr B Galland, Department of Women's and Children's Health, University of Otago, PO Box 913 Dunedin, New Zealand: barbara.galland@stonebow. otago.ac.nz

Accepted 14 August 2002

\begin{abstract}
Aim: To determine any variation in the respiratory responses to hypoxia/hypercapnia of infants born small for gestational age (SGA) to smoking and to non-smoking mothers.

Methods: A total of 70 average for gestational age (AGA) infants (>36 weeks gestation, $>2500 \mathrm{~g}$, $>25$ th centile for gestational age, and no maternal smoking), and 47 SGA infants ( $<10$ th centile for gestational age) were studied at 1 and 3 months of age, in quiet and active sleep. Respiratory test gases were delivered through a Perspex hood to simulate face down rebreathing by slowly allowing the inspired air to be altered to a $\mathrm{CO}_{2}$ maximum of $5 \%$ and $\mathrm{O}_{2}$ minimum of $13.5 \%$. The change in ventilation with inspired $\mathrm{CO}_{2}$ was measured over 5-6 minutes of the test. The slope of a linear curve fit relating inspired $\mathrm{CO}_{2}$ to the logarithm of ventilation was taken as a quantitative measure of ventilatory asphyxial sensitivity (VAS).

Results: There was no significant difference in VAS between the AGA and SGA infants (0.25 v0.24). However within the SGA group, VAS was significantly higher $(p=0.048)$ in the infants whose mothers smoked during pregnancy $(0.26(0.01) ; n=24)$ than in those that did not $(0.23(0.01) ; n=23)$. The change in minute ventilation was significantly higher in the smokers than the non-smokers group $1141 \% \vee 119 \% ; p=0.03)$ as the result of a significantly larger change in respiratory rate (8 $\vee 4$ breaths/min; $p=0.047$ ) but not tidal volume.

Conclusions: Maternal smoking appears to be the key factor in enhancing infants' respiratory responses to hypoxia/hypercapnia, irrespective of gestational age.
\end{abstract}

in nfants born small weight for gestational age (SGA) as a result of intrauterine growth retardation (IUGR) have increased morbidity ${ }^{1}$ and poorer neurological outcomes ${ }^{2}$ compared to infants born at an average weight for gestational age (AGA). SGA infants are also at higher risk of perinatal mortality ${ }^{3}$ and sudden infant death syndrome (SIDS), ${ }^{45}$ and have been linked to increased insulin resistance ${ }^{6}$ and increased long term cardiovascular morbidity and mortality. ${ }^{7}$ The relative risk of an infant being born SGA is increased twoto threefold by the influence of maternal smoking, ${ }^{89}$ and maternal smoking, after adjustment for all confounders (including SGA), increases the risk of SIDS twofold. ${ }^{10}{ }^{11}$ Many epidemiological studies have identified that the prone sleeping position is a major risk factor for SIDS. Prone sleeping dramatically increases the relative risk (odds ratios) of SIDS by 38.8 when combined with IUGR, the effect of non-supine sleeping (prone and side) being greatest at 13-24 weeks. ${ }^{4}$ The aetiology of SIDS is unknown, but failure of cardiorespiratory function and arousal are regarded as likely causes of death.

Studies of normal baseline respiratory function in SGA infants are few. One study reports delayed maturation of respiratory control inferred by the evidence of increased incidence of apnoea in SGA infants, ${ }^{12}$ suggested to be linked to subtle brain stem alterations caused by the decreased blood supply and chronic hypoxia associated with IUGR. As far as we are aware, there are no studies of respiratory function during stimulated respiration in SGA infants at birth or beyond. In the normal sleeping environment, respiration is stimulated through exposure to the combined chemical stimuli of hypoxia and hypercapnia (asphyxia), particularly if sleeping prone on soft surfaces and/or under the bedclothes. ${ }^{13}{ }^{14}$ Rebreathing expired gases (resulting in hypoxaemia/ hypercarbia) has been suggested as one of the likely mechanisms involved in some cases of SIDS..$^{13} 15$

In a previous study, we reported that infants born AGA with the prenatal SIDS risk factor of maternal smoking, had increased respiratory responses to asphyxia but responded with lower oxygen haemoglobin saturation levels, leading to the suggestion that maternal smoking caused poorer ventilation perfusion matching in these infants. ${ }^{16}$ In addition, a small number of individual infants from the smokers group, had poor protective responses to the respiratory stimuli in terms of failing to activate the appropriate respiratory response and to wake to the test. The aim of the present study was to determine the effect of another prenatal risk factor for SIDS, SGA, on the respiratory and waking response to asphyxia, and within this SGA group, the effect of maternal smoking on this response.

\section{METHODS}

Infants were recruited from the postnatal wards of the local maternity hospital. Table 1 gives demographic information on the AGA $(n=70)$ and SGA groups $(n=47)$. The criteria for AGA selection were babies $>36$ weeks weighing over $2500 \mathrm{~g}$ and $>25$ th centile for gestational age without prenatal or postnatal complications and no maternal smoking. SGA babies were selected on the basis of being $<10$ th centile for gestational age. The SGA group consisted of 23 babies whose

Abbreviations: AGA, average for gestatinal age; $A S$, active sleep; HR, heart rate; IUGR, intrauterine growth retardation; $Q S$, quiet sleep; $R R$, respiratory rate; SGA, small for gestational age; SIDS, sudden infant death syndrome; VAS, ventilatory asphyxial sensitivity; Ve, minute ventilation; $\mathrm{V}_{\mathrm{T}}$, tidal volume 
Table 1 Group characteristics

\begin{tabular}{|c|c|c|c|c|c|c|c|}
\hline Group & $\begin{array}{l}\text { Sex } \\
\text { (M/F) }\end{array}$ & $\begin{array}{l}\text { Gestation } \\
\text { (wk) }\end{array}$ & $\begin{array}{l}\text { Birth weight } \\
\text { (g) }\end{array}$ & $\begin{array}{l}\text { *Age (days) at } \\
1 \text { month study }\end{array}$ & $\begin{array}{l}\text { Weight (g) at } \\
1 \text { month study }\end{array}$ & $\begin{array}{l}\text { *Age at } \\
3 \text { month study }\end{array}$ & $\begin{array}{l}\text { Weight at } \\
3 \text { month study }\end{array}$ \\
\hline $\begin{array}{l}\text { AGA } \\
(n=70)\end{array}$ & 1.0 & $\begin{array}{l}40 \\
(37-42)\end{array}$ & $\begin{array}{l}3585 \\
(2590-4480)\end{array}$ & $\begin{array}{l}22 \\
(3-30)\end{array}$ & $\begin{array}{l}4060 \\
(2800-4900)\end{array}$ & $\begin{array}{l}86 \\
(77-102)\end{array}$ & $\begin{array}{l}6020 \\
(4700-7180)\end{array}$ \\
\hline $\begin{array}{l}\text { SGA } \\
(\mathrm{n}=47)\end{array}$ & 1.2 & $\begin{array}{l}39 \\
(33-42)\end{array}$ & $\begin{array}{l}2580 \dagger \\
(1220-3020)\end{array}$ & $\begin{array}{l}22 \\
(12-29)\end{array}$ & $\begin{array}{l}3315 \dagger \\
(2400-4070)\end{array}$ & $\begin{array}{l}90 \\
(80-100)\end{array}$ & $\begin{array}{l}5245 \dagger \\
(3660-6700)\end{array}$ \\
\hline
\end{tabular}

Median data with values in parentheses representing the ranges.

tp $<0.005 v$ corresponding factor for group.

*Adjusted post-conceptional age for those infants born preterm (<37 weeks).

mothers smoked during pregnancy. Information on the number of cigarettes mothers smoked per day over the three trimesters and after pregnancy were obtained from a questionnaire. Studies were carried out at approximately 1 month and 3 months of age. A total of 106/117 infants were studied at both ages, and the remaining 11 at either 1 month or 3 months. Nine of the SGA infants were preterm $(<37$ weeks gestation); their ages at study were adjusted accordingly.

\section{Protocol}

The babies were brought into the research nursery at Dunedin Hospital for a daytime nap study between the hours of 9 am and $1 \mathrm{pm}$. The infants were set up for recordings with placement of ECG electrodes (modified lead II position), a pulse oximeter probe around the foot and respibands around the chest and abdomen. The infants were then fed and placed to sleep supine in a pram. After at least five minutes of sleep, a Perspex head box was placed over the infant's head. Air flowed from a Douglas bag through the head box at a rate of 6-9 l/min for one minute; the flow was then switched over to the test bag containing $5.5 \% \mathrm{CO}_{2}$ and $13 \% \mathrm{O}_{2}$ in $\mathrm{N}_{2}$ which mixed with the contents of the head box to progressively alter the inspired gas mixture. The test mix was delivered for a maximum of 5-6 minutes or until the infant woke. The maximum inspired level of $\mathrm{CO}_{2}$ reached was $5 \%$ and the minimum inspired level of $\mathrm{O}_{2}, 13.5 \%$. This method of respiratory testing in infants has been described previously. ${ }^{17}{ }^{18}$ Respiratory tests were attempted twice in quiet sleep (QS) and twice in active sleep (AS). If sleep state changed during a test, the test was abandoned.

The study was approved by the Otago Ethics Committee, Dunedin, New Zealand. Informed written consent was obtained from the parent(s) of all infants studied.

\section{Recordings}

Respiratory pattern was recorded by inductive plethysmography (Respitrace model 150; Respitrace Co., NY, USA). Changes in uncalibrated tidal volume (voltage) and respiratory rate (breaths/min) from baseline were measured. The tidal volume sum of two signals analogous to the cross sectional area of the ribcage and abdomen were weighted routinely with the ratio 10:8. Heart rate and arterial oxygen saturation $\left(\mathrm{SaO}_{2}\right)$ were recorded from the pulse oximeter (Nellcor N-200, Nellcor Hayward, CA, USA) with averaging time set to three seconds. The percentage of inspired $\mathrm{O}_{2}$ and $\mathrm{CO}_{2}$ was measured from a Datex gas analyser (Normocorp 200-oxy $\mathrm{CO}_{2}-\mathrm{O}_{2}$, Datex Instumentarium Corp., Helsinki, Finland) with sample probe suspended within the head box. All signals were relayed through an integrated hardware/software system (PowerLab, ADInstruments Pty Ltd, Australia). Sleep state was determined by watching eye, mouth, hand, and respiratory trace movements based on that reviewed by Guilleminault and Soquet ${ }^{19}$ for the two age groups where quiet sleep (QS) was a state of regular breathing with no rapid eye movements or facial movements and more gross jerky movements in the 3 month infants. Active sleep (AS) contained some rapid eye movements, irregular breathing, and sometimes hand or mouth movements. Waking was defined when the infant's eyes were open with vigorous movement and/or crying.

Measurement of ventilatory asphyxial sensitivity (VAS) A single number expression for the ventilatory response to the asphyxial test (ventilatory asphyxial sensitivity, VAS) was derived from the best fit line of the relation between inspired $\mathrm{CO}_{2}$ and logarithm of standard ventilation (the product of respiratory rate and tidal volume) as described previously. ${ }^{17}$ Ventilation is presented as a percentage change from baseline and values were taken every minute over the 5-6 minutes of the test. An estimate of $\mathrm{PACO}_{2}$ was then calculated from the alveolar gas equation as follows:

$$
\dot{\mathrm{VCO}}_{2}(\mathrm{STPD})=\left(\mathrm{PACO}_{2}-\mathrm{PICO}_{2}\right) \times \dot{\mathrm{V} A}(\mathrm{BTPS}) / 863
$$

A baseline $\mathrm{PACO}_{2}$ of $35 \mathrm{~mm} \mathrm{Hg}$ was used as an average number that does not change between postnatal days 10 and $18^{20}$ and beyond. $^{21}$ Measures of respiratory dead space in infants estimate that it is approximately one third of tidal volume. ${ }^{22} \mathrm{~A}$ measure of standard tidal volume was obtained by dividing standard minute ventilation by respiratory rate (RR). Alveolar ventilation was then calculated as:

\section{$\dot{\mathrm{VA}}$ (units $/ \mathrm{min})=\mathrm{VT}-(1 / 3 \mathrm{VT}$ at time $=0) \times \mathrm{RR}$ (breaths $/$ $\min )$}

\section{Protective responses}

Protective responses to the asphyxial test combined both the ventilatory (VAS) and waking response. These were scaled on a grade of 1 to 4 , grade 1 defining the least protective response and grade 4, the most protective: grade 1 , no waking and poor ventilatory response with an estimated $\mathrm{PACO}_{2}=60 \mathrm{~mm} \mathrm{Hg}$; grade 2 , no waking and poor ventilatory response (VAS $<0.1$ ); grade 3, no waking but good ventilatory response (VAS $>0.1$ ); grade 4 , awake to the test. The delineating VAS value of 0.1 as a poor response is equivalent to only a $64 \%$ increase in alveolar ventilation with $5 \% \mathrm{CO}_{2}$ (compared to an average increase of $250-350 \%$ ) and an estimated $\mathrm{PACO}_{2}>56 \mathrm{~mm} \mathrm{Hg}$.

\section{Cotinine analysis}

Saliva samples were collected from all mothers at the time of the two studies to correlate cotinine levels with reported smoking obtained from the questionnaire. The samples were analysed blind at the Canterbury Health Laboratories using mass spectral detection (accuracy to $2 \mu \mathrm{g} / \mathrm{l}$ ).

\section{Statistical analysis}

For every infant a mean value from each asphyxial test was obtained for $\mathrm{SaO}_{2}$, respiratory frequency, tidal volume, and heart rate over a period of 10 breaths immediately before delivery of the test gas (baseline value). Mean values for the same variables were then taken over the 10 breaths immediately before the test was stopped (end values). A single 


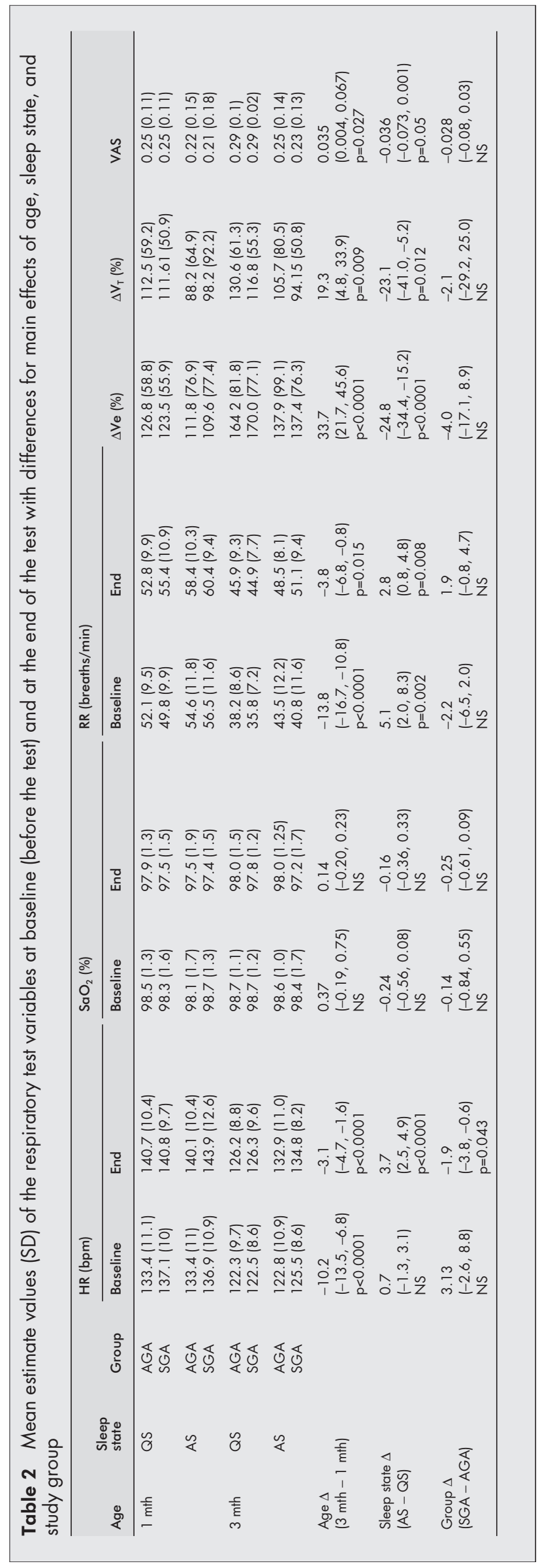

value for VAS was obtained for each test. As the data from these babies involves analysis of many interacting factors, a multivariate analysis isolating the effect of each factor (age, sleep state, gestational weight, and smoking status) in turn was adopted (STATA, Stata Statistical Software, release 6.0, Stata Corporation, College Station, TX). The standard errors and the significance of the statistical tests were based on the number of babies rather than the number of observations in the study. Main effects were analysed for age, sleep state, gestational weight, and smoking status, and interactions considered where appropriate. Logistic regression was used to compare the waking data for the factors concerned. Differences were taken as statistically significant when $p \leqslant 0.05$.

\section{RESULTS}

There was no difference between the ages of the AGA and ages or adjusted ages of the SGA infants studied at the 1 month and 3 month study (table 1). Of the 25/47 SGA babies whose mothers smoked, eight smoked on average 10-15 cigarettes/ day (during all of the pregnancy) and 17 smoked 16-25/day. All continued to smoke postnatally. There was good correlation between mother's stated smoking habits postnatally and salivary cotinine level at the time of study. The median cotinine level from samples of saliva taken from non-smoking mothers was $0 \mathrm{ng} / \mathrm{ml}$ (range 0-146) at the 1 month study and $0 \mathrm{ng} / \mathrm{ml}$ (range 0-247) at the 3 month study. From smoking mothers, the median level was $160 \mathrm{ng} / \mathrm{ml}$ (range 0-450) at the 1 month study and $193 \mathrm{ng} / \mathrm{ml}$ (range 27-437) at the 3 month study. There were no significant differences in the characteristics of the SGA infants whose mothers smoked and those that did not in terms of gestational age or weight, or adjusted weight at birth.

\section{Respiratory test variables: SGA v AGA}

Table 2 presents respiratory test variables. Infants at the older age of 3 months had significantly lower heart rate (HR) and RR than younger infants. HR and RR were higher in AS compared to QS. These differences were consistent at rest (baseline) and at the end of the respiratory test. HR at the beginning of the test was similar between SGA and AGA infants but by the end of the test, the heart rate of SGA infants was slightly but significantly lower. There was no difference in $\mathrm{SaO}_{2}$ at the start or end of the test with age, sleep state, or study group. Older infants responded to the test with a greater increase in the percentage change in minute ventilation (Ve), tidal volume $\left(\mathrm{V}_{\mathrm{T}}\right)$, and absolute change in $\mathrm{RR}$, and in the value for VAS. The test applied in AS compared to QS resulted in smaller changes in Ve, $\mathrm{V}_{\mathrm{T}}, \mathrm{RR}$, and VAS, but comparison by study group (AGA $v$ SGA) produced no significant difference.

\section{Respiratory test variables: SGA (smokers v non-smokers)}

Figure 1 illustrates the estimated mean respiratory test differences and 95\% confidence intervals between the smokers' and non-smokers' infants. The mean data combine age and sleep state values as the age and sleep state effects (within the nonsmokers and smokers study groups) were similar to those described above and given in table 2 .

HR at the start of the test was similar between smokers' and non-smokers' infants, but there was a significantly larger increase in heart rate $(p=0.001)$ induced by the respiratory test in the smokers' infants. The change in minute ventilation in response to the respiratory test was significantly higher $(p=0.03)$ in the smokers than the non-smokers group ( $141 \%$ $v 119 \%)$. This was the result of a significantly larger increase in respiratory rate ( $8 v 4$ breaths/min; $\mathrm{p}=0.047$ ) but not tidal volume. Smoking status did not influence $\mathrm{SaO}_{2}$. VAS was significantly higher $(p=0.048)$ in the infants whose mothers smoked during pregnancy than in those that did not. 


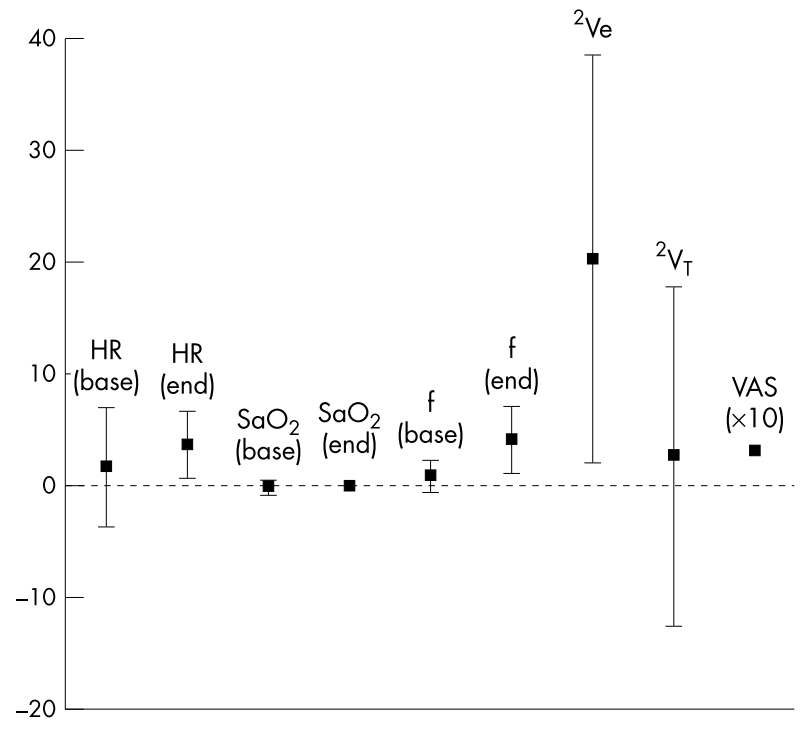

Figure 1 Estimated mean $(95 \% \mathrm{Cl})$ difference between smokers' and non-smokers' infants for the respiratory test variables.

\section{Protective responses}

The majority of protective responses were grade 3 (no waking and a VAS $>0.1$; table 3 ). When waking occurred, the test was terminated early and the inspired gas levels of $\mathrm{CO}_{2}$ and $\mathrm{O}_{2}$ were $4.24 \%$ (CI 4.20 to 4.28 ) and $15.0 \%$ ( 14.95 to 15.04$)$ respectively, compared with $4.85 \%$ and $14.0 \%$ respectively (no waking). Sleep state was the only factor that changed the likelihood of waking: the test given in AS compared to QS increased the chances of waking sixfold. There were no significant interaction effects and no sleep state or group effects. Comparison of the protective responses of SGA non-smokers $v$ smokers group resulted in no significant difference.

\section{DISCUSSION}

We have shown that SGA infants with no history of maternal smoking during the period of gestation have normal ventilatory and arousal responses to a respiratory challenge of progressive hypoxia/hypercapnia. However, SGA infants with a history of maternal smoking showed an increase in ventilatory sensitivity to the respiratory challenge. The findings strengthen our previous work in that infants born at the appropriate weight for gestational age (AGA) and exposed to maternal smoking during pregnancy, also showed an increase in ventilatory sensitivity to progressive hypoxia/ hypercapnia. ${ }^{16}$
A mechanism for this increase in ventilatory sensitivity to hypoxia/hypercapnia is unknown. It is possible that our findings are related to differences in airway structure between smokers' and non-smokers' infants as a result of either lung damage and/or poor growth. In a previous study of AGA infants we observed a small deficit in oxygen saturation in smokers' infants' responses to hypoxia/hypercapnia despite enhanced ventilatory sensitivity. ${ }^{16}$ This is consistent with the analogy that thickened airways would produce a degree of ventilation/perfusion mismatching, which would result in a degree of hypoxaemia despite mild hyperventilation. Experimental animal studies of prenatal hypoxaemia (which may occur secondary to nicotine exposure) suggest significant effects on lung development, with a thickened air-blood barrier in the fetus and a lower diffusing capacity after birth. $^{23}$ Consequently respiratory function is adversely effected. ${ }^{23}{ }^{24}$ Several studies have shown that respiratory dysfunction suggesting mild lung damage in smokers' infants, or poor lung growth, is evident in infants born preterm, ${ }^{25}$ at term, ${ }^{26}$ and beyond. ${ }^{28}{ }^{29}$ However, some studies have not shown this beyond the neonatal period. ${ }^{30}{ }^{31}$ Elliot et al have shown that airway wall thickness of SIDS infants exposed to maternal smoking in utero is increased compared to that of SIDS infants not exposed to maternal smoking. ${ }^{32}$ Poor lung growth is suggested by studies in mice where prenatal nicotine exposure results in significant electron microscopic alterations in small airway development. ${ }^{33}$ Furthermore, injecting pregnant rats with nicotine results in significantly smaller lung mass attributed to smaller cell size with enhanced cell proliferation confined to the neonatal period. ${ }^{34}$

Similar findings of enhanced ventilatory responses to hypercapnia have been reported in guinea pig pups where the dams were exposed to carbon monoxide (a toxic constituent of cigarette smoke) during the period of gestation..$^{35}$ Poole et al, in a study of AGA smokers' infants at 8-10 weeks of age, reported higher end tidal oxygen levels in smokers' infants during inspiration of an hyperoxic $\left(40 \% \mathrm{O}_{2}\right)$ mix which immediately followed administration of a hypoxic $\left(0 \% \mathrm{O}_{2}\right)$ mix. ${ }^{36}$ This could be explained by a higher ventilatory response to the preceding hypoxic mix in smokers' infants with increased tidal volume. They, however, reported no difference in tidal volume between groups, but because of the brief and alternating nature of the test together with their variable response, a subtle difference in $\mathrm{V}_{\mathrm{T}}$ between smokers' and non-smokers' infants may not have been able to be accurately detected.

We have no way of knowing whether the increase in ventilatory sensitivity to hypoxia/hypercapnia was caused by prenatal or postnatal smoking, as the two factors are inseparable. From the findings that lung mechanics are disturbed at newborn age in infants exposed to maternal smoking, ${ }^{37}$ we speculate that the effect is related to prenatal rather than postnatal smoking, but could be further exacerbated by postnatal smoking. Impaired respiratory function is

\begin{tabular}{|c|c|c|c|c|c|}
\hline & $\begin{array}{l}\text { Grade } 1 \\
\text { (calculated PACO } \\
\geqslant 60 \mathrm{mmHg} \text { ) }\end{array}$ & $\begin{array}{l}\text { Grade } 2 \\
(\text { VAS < } 0.1)\end{array}$ & $\begin{array}{l}\text { Grade } 3 \\
\text { (VAS }>0.1 \text { ) }\end{array}$ & $\begin{array}{l}\text { Grade } 4 \\
\text { (awake) }\end{array}$ & $\begin{array}{l}\text { Total no of } \\
\text { tests }\end{array}$ \\
\hline \multicolumn{6}{|l|}{ Age } \\
\hline 1 month & $2 \%$ & $6 \%$ & $73 \%$ & $19 \%$ & 293 \\
\hline 3 months & $1 \%$ & $3 \%$ & $81 \%$ & $15 \%$ & 256 \\
\hline \multicolumn{6}{|l|}{ Sleep state } \\
\hline QS & $1 \%$ & $3 \%$ & $90 \%$ & $6 \%$ & 283 \\
\hline AS & $2 \%$ & $6 \%$ & $63 \%$ & $29 \%$ & 264 \\
\hline \multicolumn{6}{|l|}{ Group } \\
\hline AGA & $1 \%$ & $5 \%$ & $79 \%$ & $15 \%$ & 347 \\
\hline SGA & $2 \%$ & $3 \%$ & $74 \%$ & $21 \%$ & 201 \\
\hline $\begin{array}{l}\text { The likelihoo } \\
\text { Age } 13 \text { mont } \\
\text { Sleep state ( } \\
\text { Group (SGA }\end{array}$ & $\begin{array}{l}\text { fants waking (grade } \\
\text { month), } 1.0 \text { (NS) } \\
2 S), 6.0 \text { (p<0.0001) } \\
\text { A), } 1.6 \text { (NS) }\end{array}$ & not waking & des 1,2 , an & was for: & \\
\hline
\end{tabular}


evident in infants born on average less than seven weeks prior to term-suggesting that adverse effects of prenatal exposure are not limited to the last weeks of pregnancy. ${ }^{25}$

Another angle to consider as a mechanism for the increase in ventilatory sensitivity to hypoxia/hypercapnia is the effect of smoking on respiratory neurotransmitter pathways. Several experimental studies in rats have shown that prenatal exposure to nicotine (the major constituent of cigarette smoke), affects a wide range of central neural system developments that could alter neruotransmission, for example, distribution of neural catecholamines, ${ }^{38}$ the density of striatal muscarinic cholinergic receptors, ${ }^{39} \mathrm{D} 2$ dopamine binding in the basal ganglia, ${ }^{40}$ and uptake of 5 -HT in rat brain stem. ${ }^{41}$ An effect of nicotine on carotid body development might also be expected, given that nicotinic cholinergic receptors are present on type I cells, ${ }^{42}$ and acute nicotine stimulates carotid body discharge.$^{43}$ It has been suggested that effects may be subtle and only apparent under conditions that deviate from normal, such as those activating respiratory defence mechanisms. The few experimental animal studies to test this have reported different findings. Hafstrom et al, in a study of lambs prenatally infused with nicotine, found a depressed ventilatory response to hypoxia, ${ }^{44}$ whereas Bamford et al, in a study of rat pups exposed to nicotine through prenatal infusion of the dams using miniosmotic pumps, ${ }^{45}$ found no change in the ventilatory response to hypoxia or hypercapnia. The equally few human infant studies also report different findings. Lewis and Bosque ${ }^{46}$ found no difference in ventilatory responses to hypoxia or hypercapnia between their 13 smokers' and 34 non-smokers' infants. In contrast, in two much larger studies we found an enhanced response to the combined hypoxia/ hypercapnia stimulus in smokers' infants in this, and in our previous study of AGA infants. The pure hypoxia or hypercapnia stimulus would rarely be encountered in "real life".

Our test was more likely to wake infants in active sleep than quiet sleep. We found no deficiency in waking responses between groups, unlike our previous study of AGA infants of smoking mothers who were more likely to wake to the asphyxia test than control infants. This was possibly because their arterial oxygen levels became lower in response to the test, a finding not apparent in the current study.

In the present study, the enhanced ventilatory response to asphyxia in smokers' versus non-smoker's infants was attributed to an increase in respiratory rate, whereas in the previous study of larger infants (AGA), the major difference was attributed to an increase in tidal volume. This difference may be purely a function of lung mechanics as it is reasonable to assume that the smaller SGA infants will have less margin to increase tidal volume and increase ventilation.

In terms of the baseline respiratory rate, data were similar between SGA and AGA infants for both sleep state and age related changes. This is a consistent finding with the only other study, by Curzi-Dascalova et al, that has reported baseline respiratory characteristics in SGA infants. ${ }^{12}$ CurziDascalova et al did, however, find that the SGA infants showed a delay in establishing respiratory rhythm control suggested through the higher incidence of respiratory pauses. We found that baseline heart rate data values were similar between groups, but within the SGA infants there was a significantly larger increase in heart rate in smokers' infants induced by the respiratory test, consistent with the metabolic demands of the enhanced ventilatory response.

The findings showing a higher ventilatory response with maturation over the three month period are in agreement with our previous data ${ }^{17}$ and probably reflect a maturation of the ventilatory system together with improved chemosensitivity. A lowered ventilatory response in active sleep compared to quiet sleep has been previously documented for hypercapnia and hypoxia ${ }^{47} 48$ and asphyxia, ${ }^{17}$ linked to a loss of intercostal muscle tone and consequent decrease in the ribcage contribution to ventilation, inhibition of abdominal muscle recruitment, and a decrease in central output to the diaphragm.
In conclusion, the findings strengthen our previous work in showing that maternal smoking appears to be the key factor in enhancing ventilatory responsiveness to hypoxia/ hypercapnia. ${ }^{16}$ Our findings do not support the view that sudden infant deaths associated with maternal smoking result from depressed responsiveness to respiratory stimuli and do not help to explain why infants that are SGA after controlling for all confounders (including maternal smoking) are still at increased risk of SIDS. We suggest that through alterations in lung mechanics, these infants are more likely to become fatigued, and together with poor ventilation perfusion matching, be subject to respiratory and cardiac failure.

\section{ACKNOWLEDGEMENTS}

This study was supported by the Health Research Council of New Zealand and in part by the Cot Death Association of New Zealand. The authors are grateful to Mrs Sheila Williams for statistical analysis and to the many parents who gave consent for their babies' participation.

...................

Authors' affiliations

B C Galland, B J Taylor, R M Sayers, Department of Women's and Children's Health, Otago Medical School, Dunedin, New Zealand D P G Bolton, Department of Physiology, Otago Medical School

\section{REFERENCES}

1 Ounsted M, Moar V, Scott WA. Perinatal morbidity and mortality in small-for-dates babies: the relative importance of some maternal factors. Early Hum Dev 1981:5:367-75.

2 Ounsted M, Moar VA, Scott A. Neurological development of small-for-gestational age babies during the first year of life. Early Hum Dev 1988;16:163-72.

3 Witter FR. Perinatal mortality and intrauterine growth retardation. Curr Opin Obstet Gynecol 1993;5:56-9.

4 Oyen N, Markestad T, Skaerven R, et al. Combined effects of sleeping position and prenatal risk factors in sudden infant death syndrome: the Nordic Epidemiological SIDS Study. Pediatrics 1997;100:613-21.

5 Veelken N, Ziegelitz J, Knispel JD, et al. Sudden infant death syndrome in Hamburg. An epidemiological analysis of 150 cases. Acta Paediatr Scand 1991;80:86-92.

6 Gluckman PD, Cutfield W, Harding JE, et al. Metabolic consequences of intrauterine growth retardation. Acta Paediatr Suppl 1996;417:3-6.

7 Barker DJ. Fetal nutrition and cardiovascular disease in later life. BM 1997:53:96-108.

8 Scott A, Moar V, Ounsted M. The relative contributions of different maternal factors in small-for-gestational-age pregnancies. Eur J Obstet Gynecol Reprod Biol 1981;12:157-65.

9 Chan A, Keane RJ, Robinson JS. The contribution of maternal smoking to preterm birth, small for gestational age and low birthweight among Aboriginal and non-Aboriginal births in South Australia. Med J Aust 2001; 174:389-93.

10 Mitchell EA, Taylor BJ, Ford RPK, et al. Four modifiable and other risk factors for cot death: the New Zealand study. J Paediatr Child Health 1992;28:S3-8.

11 Anderson HR, Cook DG. Passive smoking and sudden infant death syndrome: review of the epidemiological evidence. Thorax 1997;52:1003-9.

12 Curzi-Dascalova L, Peirano P, Christova E. Respiratory characteristics during sleep in healthy small-for-gestational age newborns. Pediatrics 1996;97:554-9.

13 Bolton D, Taylor B, Campbell A, et al. Rebreathing expired gases from bedding: a cause of cot death? Arch Dis Child 1993;69:187-90.

14 Campbell AJ, Bolton DPG, Taylor BJ. A potential danger of bedclothes covering the face. Acta Paediatr 1996:85:281-4.

$15 \mathrm{Kemp}$ JS. Rebreathing of exhaled gases: importance as a mechanism for the causal association between prone sleep and sudden infant death syndrome. Sleep 1996;19:S263-6.

16 Campbell AJ, Galland BC, Bolton DPG, et al. Ventilatory response to rebreathing in infants exposed to maternal smoking. Acta Paediatr 2001;90:793-800

17 Campbell AJ, Bolton DPG, Taylor BJ, et al. Responses to an increasing asphyxia in infants: effects of age and sleep state. Respir Physiol 1998;112:51-8.

18 Galland BC, Bolton DPG, Taylor BJ, et al. Ventilatory sensitivity to mild asphyxia: prone versus supine sleep position. Arch Dis Child 2000;83:423-8

19 Guilleminault C, Souquet M. Sleep states and related pathology. In: Korobkin R, Guilleminault C, eds. Advances in perinatal neurology. New York: Spectrum Publications, 1979:225-47.

20 Stahlman $M$. Ventilation control in the newborn: carbon dioxide tension and output. Am J Dis Child 1961;101:216-27.

21 Carse EA, Wilkinson AR, Whyte PL, et al. Oxygen and carbon dioxide tensions, breathing and heart rate in normal infants during the first six months of life. J Develop Physiol 1981;3:85-100. 
22 Fowler WS. Lung function studies II. The respiratory dead space. Am J Physiol 1948;154:405-16.

23 Harding R, Tester ML, Moss TJ, et al. Effects of intra-uterine growth restriction on the control of breathing and lung development after birth. Clin Exp Pharmacol Physiol 2000;27:1 14-19.

24 Harding R. Sustained alterations in postnatal respiratory function following sub-optimal intrauterine conditions. Reprod Fertil Dev 1995;7:431-41

25 Hoo AF, Henschen M, Dezateux C, et al. Respiratory function among preterm infants whose mothers smoked during pregnancy. Am J Respir Crit Care Med 1998;158:700-5.

26 Lodrup Carlsen KC, Jaakkola JJ, Nafstad P, et al. In utero exposure to cigarette smoking influences lung function at birth. Eur Respir $J$ 1997:10:1774-9.

27 Stick SM, Burton PR, Gurrin L, et al. Effects of maternal smoking during pregnancy and a family history of asthma on respiratory function in newborn infants. Lancet 1996;348:1060-4

28 Hanrahan JP, Tager IB, Castile RG, et al. Pulmonary function measures in healthy infants. Variability and size correction. Am Rev Respir Dis 1990;141:1127-35.

29 Young S, Le Souef PN, Geelhoed GC, et al. The influence of a family history of asthma and parental smoking on airway responsiveness in early infancy. N Engl J Med 1991;324:1 168-73.

30 Martinez FD, Morgan WJ, Wright AL, et al. Diminished lung function as a predisposing factor for wheezing respiratory illness in infants. N Engl J Med 988:319:1112-17.

31 Clarke JR, Salmon B, Silverman M. Bronchial responsiveness in the neonatal period as a risk factor for wheezing in infancy Am J Respir Crit Care Med 1995;151:1434-40.

32 Elliot J, Vullermin P, Robinson P. Maternal cigarette smoking is associated with increased inner airway wall thickness in children who die from sudden infant death syndrome. Am J Respir Crit Care Med 1998;158:802-6.

33 Wang NS, Chen MF, Schraufnagel DE, et al. The cumulative scanning electron microscopic changes in baby mouse lungs following prenatal and postnatal exposures to nicotine. J Pathol 1984;144:89-100.

34 Maritz GS. Effect of maternal nicotine exposure on growth in vivo of lung tissue of neonatal rats. Biol Neonate 1988;53:163-70.

35 McGregor HP, Westcott K, Walker DW. The effect of prenatal exposure to carbon monoxide on breathing and growth of the newborn guinea-pig. Pediatr Res 1998;43:126-31.
36 Poole KA, Hallinan $\mathrm{H}$, Beardsmore CS, et al. Effect of maternal smoking on ventilatory responses to changes in inspired oxygen levels in infants. Am J Respir Crit Care Med 2000;162:801-7.

37 Brown RW, Hanrahan JP, Castile RG, et al. Effect of maternal smoking during pregnancy on passive respiratory mechanics in early infancy. Pediatr Pulmonol 1995;19:23-8.

38 Ribary U, Lichtensteiger W. Effects of acute and chronic prenatal nicotine treatment on central catecholamine systems of male and female rat fetuses and offspring. J Pharmacol Exp Ther 1989;248:786-92.

39 Zahalka EA, Seidler FJ, Yanai J, et al. Fetal nicotine exposure alters ontogeny of $\mathrm{Ml}$-receptors and their link to G-proteins. Neurotoxicol Teratol 1993;15:107-15.

40 Fuxe K, Goldstein M, Janson AM. Chronic nicotine treatment decreases dopamine D2 agonist binding in the rat basal ganglia. Clin Invest 1992;70:232-8

41 Strickler G, King D, Higgins ST, et al. Differential effects of prenatal and postnatal ACTH or nicotine exposure on 5-HT high affinity uptake in the neonatal rat brain. Pharmacol Biochem Behav1989;34:149-55.

42 Wyatt CN, Peers C. Nicotinic acetylcholine receptors in isolated type I cells of the neonatal rat carotid body. Neuroscience 1993:54:275-81.

43 Lahiri S, Mokashi A, Matsumoto S, et al. Cat carotid body chemoreceptor responses before and after nicotine receptor blockade with alpha-bungarotoxin. Respir Physiol 1986;63:375-82.

44 Hafstrom O, Milerad J, Poole SD, et al. Prenatal nicotine exposure impairs the cardiorespiratory response to acute hypoxemia in sleeping lambs. Pediatr Res 1997;41:302A.

45 Bamford OS, Schuen JN, Carroll JL. Effect of nicotine exposure on postnatal ventilatory responses to hypoxia and hypercapnia. Respir Physiol 1996;106:1-11.

46 Lewis KW, Bosque EM. Deficient hypoxia awakening response in infants of smoking mothers: possible relationship to sudden infant death syndrome. J Pediatr 1995;127:691-9.

47 Honma Y, Wilkes D, Bryan MH, et al. Rib cage and abdomina contributions to ventilatory response to $\mathrm{CO} 2$ in infants. J Appl Physiol 1984;56:1211-16.

48 Moriette G, Van Reempts P, Moore M, et al. The effect of rebreathing $\mathrm{CO} 2$ on ventilation and diaphragmatic electromyography in newborn infants. Respir Physiol 1985;62:387-97.

\section{This month in the Archives of Disease in Childhood}

The following papers appearing in the May 2003 issue of $A D C$ may be of interest to readers of Fetal and Neonatal.

Leading article

Recent developments in lasers and the treatment of birthmarks $M$ Waner

Review

Group B streptococcal conjugate vaccines C J Baker, M S Edwards

Original article

Survival of children born with congenital anomalies S Dastgiri, W H Gilmour, D H Stone 